\title{
PADRÕES DE COMUNICAÇÃO E DE COMPORTAMENTO DOS EMPRESÁRIOS JAPONESES NO BRASIL
}

\author{
Hiroshi Saito \\ Universidade de São Paulo
}

Nota prévia

Para início da conversa, devo dedicar algumas palavras sobre a presença japonesa no Brasil.

Hoje, a coletividade de origem japonesa no Brasil é estimada em torno de 750 mil. Tudo começou com a chega da do primeiro grupo de imigrantes em 1908 a bordo do lendário Kasato-Maru. E até o ano de 1941, quando se interrompeu a corrente imigratória devido à eclosão da guerra no Pacífico, chegaram a este país aproxima damente 190 mil imigrantes.

No após-guerra, a corrente foi retomada a partir de 1953 e chegaram até 1979 pouco mais de $60 \mathrm{mil}$. Somando-se os $190 \mathrm{mil}$, de antes da gue ra, chegaram ao Brasil cerca de 250 mil, população que, hoje, acrescida de seus filhos e netos, alcança a cifra respeitosa de 750 mil japoneses e descendentes.

A presença japonesa no Brasil remonta, assim, a mais de 70 anos de experiência e vivência no País que a acolheu.

Grosso modo, a história vivida por esses imigrantes pode ser dividida em 3 fases:

1ạ fase, de 1908 a 41 - época em que se notou a predominância de imigrantes agricultores, sendo, em maioria, de colonos encaminhados às fazendas de café;

2a fase, de 1950 a 65 - Continuação da imigração, com chegada de novos contingentes, embora em número bastante reduzido; de outra parte, o desenvolvimento de novas gerações e com ele, a diversificação ocupacional.

3ạ fase, de 1965 a 75 - A imigração ou transferência, em grande número, de empresas japonesas.

É justamente a 3ạ fase que pretendo abordar com maior ênfase. 
Os dez anos compreendidos entre os anos de 1965 e 75 representam a fase de transferéncia maciça de empresas japonesas para o Brasil, favorecida essa Iransferência, de um lado, peìa rápida expansão industrial do Japão nos anos de $60 \mathrm{e}$, de outro. pelas condições propícias que o Brasil oferecia naquele período do chamado "milagre brasileiro" A transferência de empresas, que constituiu uma nova abertura no relacionamento entre o Brasil e Japão, abrange hoje várias centenas de empresas, de portes variados e de atividades diversificadas.

Conforme levantamento feito por uma fonte especializada, o Anuário de Empresas Japonesas no Brasil - 1981, existem no País cerca de 700 empresas, fundadas e/ou mantidas por japoneses e descendentes. Dessas,

- 350 empresas, inclusive cooperativas, pertencem aos migrados e descendentes, sendo portanto praticamente nacionais ou nativas;

-- 350 empresas, de maior porte que se transferiram do Japão para o Brasil no período de a pós-guerra, especialmente nos últimos 20 anos.

1)as últimas 350 empresas, 70 são de "joint-venture" que têm como seu parceiro as empresas brasileiras. Quanto a ramos de atividades, as 350 empresas japonesas dividem-se em:

- Indústria Química: 68

- Indústria Mecânica: 63

-- Indústria de produtos alimentícios: 35

-- Indústria Metalú rgica e de mineração: 33

- Indústria Elétrica e Eletrônica: 61

- Indústria Textil: 45

- Fabricação dos meios de transporte: 20

Com que objetivos teriam vindo essas 350 empresas a transferir-se para o Brasil? Segundu uma pesquisa recentemente realizada, os objetivos a que visaram ao transferir-se para o Brasil, as respostas foram as seguintes, na ordem de importância:

1 - Expansão e conquista de novos mercados;

2 - Coleta de informações, i.e., expansão da rede de informações (especialmente no caso de trading companies);

3 -.. Substituição das importações (devido à barreira alfandegária, será de maior vantagem a instalação da indústria);

4 -. Exportação para o Japão e outros países;

5 - Potencial do mercado brasileiro que possibilita um crescimento muito rápido; 
6 - Obtenção de matéria-prima para suas indú strias;

7 - Transferência de tecnologia que traria benefícios em forma de patentes e royalities.

De fato, a contribuição que algumas empresas trouxeram no campo da substituição das importações já é notória nos seguintes casos:

- Construção naval (Ishibrás), equipamentos pesados (CBC e outras);

- Motonivelador, trator e outros implementos agrícolas (Komatsu, Yanmar, Kubota e outras); Motocicletas (Honda, Yamaha, Suzuki); Instrumentos de precisão; Indústria Eletrônica, telecomunicação, televisor a cores.

No que toca à transferência de empresas, é importante notar o processo de adaptação por que passam as empresas em termos do comportamento de empresários e da tecnologia gerencial.

\section{Estratégias de adaptaçẫo}

A tecnologia gerencial dos executivos japoneses é um produto misto, elaborado a partir da tradição cultural daquele povo e "refinado" e "temperado" pelos modernos métodos de administração do mundo ocidental. A transferência de empresas japonesas para o ambiente social brasileiro, seja em forma de "joint-venture" seja em outrạ formas, implica numa série de revisão e conseqüente adaptação daquela tecnologia gerencial. Como em todo o caso de aculturação, a tentativa de aplicação de técnicas e procedimentos japoneses no meio brasileiro, encerra as possibilidades de contribuição criativa para $o$ mundo empresarial brasileiro.

Para se abordar, entretanto, os padrões de comportamento e de comunicação dos empresários japoneses, torna-se quase que imperativo buscar suas origens na própria cultura japonesa, seu sistema de valores e seus padrões de comportamento. Vê-se, que os sistemas de decisão e comunicação que caracterizam o comportamento das empresas japonesas são derivados diretamente da cultura que o povo japonês vem cultuando há dezenas de séculos.

Entre os variados padrões de comportamento ou princípios que norteiam o dia-a-dia do relacionamento social do japonês, vou destacar apenas alguns que me parecem de maior destaque:

\section{a) Complexo de senioriclade}

Em primeiro lugar, o complexo de senioridade que diz respeito a um 
sistema de precedencia. Há no relacionamento social, três categoriąs de tratamento:

- Kôhai novate, jú nior;

- Dôhai colega, companheiro;

- Sempai - veterano, sênior.

Esse princípio á válido praticamente em todos instantes do relacionamento humano, seja nas escolas e locais de trabalho, seja nas repartiçôes pú blicas. Em se tratando de escolas, um ex-aluno ou aluno antigo é sempre sempai em relação aos qie se formam mais tarde; os da mesma classe ou turma, são lôhai e aqueles que terminam curso mais tarde, são kôhai. Nas empresas e repartiçōes, os mais antigos o sempai, os mais novos, o kôhai e aqueles que foram admitidos no mesmo ano, o dôhai. Em termos de linguagem e comportamento, há diferenças nítidas entre pessoas que pertencem a diferentes categorias.

Esse sistema de precedência funciona em diversas ocasiões: o lugar de assento nas reuniôes, no embarque e desembarque de veículos e assim por diante.

b) "Nós"e "outros" (We-groitp vs They-group)

E mais um problema de identidade. A "nossa empresa" e "outras empresas" "nossa escola" e "outras escolas" Nas empresas de pequeno e médio porte, o presidente é comumente chamado de "pai" (oyaji). Quer dizer que ele está no topo de "sempai"

Semelhança com coronelismo, o cacique industrial, o apadrinhamento da sociedade brasileira. Só que na sociedade japonesa, o sistema funciona no binômio "nós" e "outros"

1) O termo gaijin indica em japonês todo o alienígena. Quem não é japonês, é gaijin. Não há meio termo, nem específico. Quaisquer que sejam as origens e nacionalidades, todo o alienigena é indistintamente gaijin.

Uin outro termo equivalente a gaijin, é a palavra Ketô. O termo é composto de $\mathrm{Ke}$ (pelo) e lô (China antiga). Antes do século XVI, quando se deu contato com os ocidentais, o estrangeiro, para os japoneses cra quase que unicamente o chinês. Quando os poitugueses e holandeses apareceram nas ilhas japonesas, o povo batizou-os com o designativo de Ketô (chinês peloso) para diferenciá-los dos chineses.

2) Os japoneses encontraram no Brasil situações inéditas. Com a chega da de filhos e netos, brasileiros de fato e direito, seriam estes gaijin por serem de nacionalidade brasileira? Evidentemente, não. Adotou-se a fórmula generalizada de tratá los como nissei (segunda geração), neologismo transplantado 
dos Estados Unidos, ou então, chamá-los de nikkei-jin (elementos de origem japonesa) ou, mais formalmente, de nikkei-brasil-jin (brasileiros de origem japonesa).

No que toca à sua identidade, os japoneses radicados no Brasil estão perdendo a consciência de We-group perante a população nacional.

c) Padrão coletivista de comportamen to

O padrão está presente praticamente em todas as situações sociais, servindo de apoio e base a dois princípios acima referidos.

Muitas vezes, o interesse do grupo pode prevalecer sobre o interesse de seus membros; o interesse da coletividade sobre o interesse individual ou pessoal.

A prevalência do interesse coletivo sobre o individual faz com que o japonês tenha pouca individualidade ou se marque pela ausência do individualismo ocidental, de caráter auto-afirmativo.

Muitos elementos da cultura japonesa são exemplos dessa reduzida individualidade. Haja vista, por exemplo, às características do tradicional quimono. Em geral, o quimono é de tamanho único tanto para mulheres como para homens. Por meio de faixa (obi) pode-se regular ou ajustar conforme a estatura da pessoa. Ainda mais, a mulher usa uma faixa maior e vistosa, a qual, chegando à altura dos seios, pode neutralizar as saliências do peito feminino, sejam estas maiores ou menores.

Outro exemplo refere-se ao furoshiki, um tipo de lenço que os japoneses usam para embrulhar as coisas. Ao contrário do equivalente ocidental, a pasta, bolsa ou valise o furoshiki não tem forma pré-determinada; a sua forma é determinada por seu conteúdo. E quando não há o que embrulhar é dobrado e guardado no bolso.

\section{Sistema de decisão e comunicação}

Os princípios básicos de comportamento que os japoneses seguem no dia-a-dia de seu relacionamento social, estão também presentes nos sistemas de decisão e comportamento das empresas japonesas. Limito-me aqui a destacar apenas quatro aspectos do problema:

1. Seniority Wage system (sistema salarial por antiguidade)

2. Life-time employment (Emprego vitalício)

3. Espírito de $W A$ (harmonia)

4. Sistema sindical 
1) Sistema salarial por antiguidade - Naturalmente esse sistema não é apenas de saláric, mas refere-se também às posições e status que a pessoa ocupa den tro de uma empresa.

Com a antiguidade, ele vai subindo na escala funcional da empresa e com isso, ele terá benefícioss extra-salariais, além do aumento gradativo de salário. Há muitas outras varıtagens que são inerentes a cada nível que a pessoa ocupa dentro de uma mesma empresa.

E çuanto mais antigo, é maior a probabilidade de ocupar posições mais eleviılas, até pelo menos alcançar a idade de aposentadoria, aos 55 anos de idade. A aposentádoria é compulsória, mas se a pessoa, galgando a posição, faz parte da diretoria, estará livre desse limite de idade. Do caso contrário, ele terá pelo menos a garantia de ocupar uma posição semelhante numa empresa subsidiária da principal. Terá pelo menos garantido um posto qualquer nessa organização empresarial. Isto quer dizer que o sistema de senioridade representa realmen ie estabilidade no cargo ou na função.

E esse sentido do segurança que, de certa forma, contribui para que a pessoa tenha o sentimento de lcuidade com a empresa; que ele seja um elemento fiel à orghanikação.

2) Emprego Vitilício - Esse sentimento de lealdade está intimamente ligádo com um oulro princípio que é o emprègo vitalício. Já que uma vez admitida numa empresa, a pessoa sempre tem a garantia de estabilidade até pelo menos alcançar a idade de 55 anos e Jepois disso, uma outra garantia semilhante para conseguir um posto qualquer em outras organizações. Isso faz com que se fortaleça o sentimento de filiação, de lealdade, para com a empresa, tornando mais coesa a solidariedade do "nosso grupo" do pessoal pertericente à mesma empresa.

Há uma certa lógica, porque, depois de a pessoa alcançar uma posição, digamos, de comando de nível intermediário, de dez a quinze anos de trabalho na empresa se ela abandonar a posição para procurar uma outra empresa dificilmente terá garantia de conseguir seu objetivo. Tudo isso faz com que esses dois princípios sejain válidos, que sejam comuns na grande maioria das empresas japonesas, priucipalmente, de grande porte. Empresas de porte médio e pequeno nem sempre podem garantir, as vantagens marginais e extra-salariais a longo dos anos de serviços. Mas, nas grandes empresas - dizem alguns analistas - justamente esses dois sistemas foram responsáveis pela solução e superação da dificuldade quando da sobrevinda da crise energética em 1973.

3) WA - Espírito de wa tem muitas implicações. Muitos empresários japoneses dão grande importância ao espírito de ua, de harmonia, que os analistas das empresas japonesas chamam de "consenso" como acontece, por exemplo, no processo decisório de "ringi" que é um sistema para conseguir consenso, para que a decisão seja consensual, que todo pessoal de vários se- 
tores de uma empresa estejam cientes de uma determinada tomada de posição ou de decisão.

O processo consensual é simbolizado pelo espírito de wa. Num livro, de tipo manuai para assalariados, está escrito que o padrão ideal para um chefe de seção (posto comando de nível intermediário) seria aquela figura que pode impor aos subordinados, trabalhos excessivamente duros e pesados; mas que em contra partida ele se preocupa com problemas que os subordinados têm, inclusive de suas famílias e mesmo fora de serviço. Um tipo de chefe considerado ideal. Ao passo que, um chefe considerado mau, de má reputaçáo, é aquele que não manda e não sabe se impor, mas também não se preocupa com os problemas que seus subordinados têm. Tudo isso demonstra como é importante este consenso dentro de um departamento ou de uma seção, nas empresas japonesas.

4) Sistema sindical - O sindicato no Japão é muito diferente do sistema ocidental. Os sindicatos são organizados em escala empresarial, isto é, cada empresa tem seu sindicato e conforme setores de atividade, os sindicatos têm filiação a associações ou federações. Mas em sua unidade individual, cada sindicato pertence a uma determinada empresa. Acontece então que, quando a empresa está em situação muito difícil, o sindicato também faz parte desse processo consensual da empresa. Quando a empresa está em fase de prosperidade, o sindicato está também participando desta prosperidade.

Muitos dirigentes das empresas japonesas dizem que a empresa e o sindicato têm destino e sorte em comum, porque quando a empresa enfrenta crises, dificuldades terão também os trabalhadores e por isso estes têm que estar cientes disso e o sindicato deve comportar-se de acordo com a situação da empresa. Existe ligação íntima entre a situação da empresa e comportamento sindical. Embora sindicatos pertençam à Federação dos Sindicatos da Indústria Metalú rgica ou dos Bancários, cada sindicato está ligado a uma empresa. De modo que, tudo faz com que as empresas japonesas, com base nesses padrões culturais de comportamento, apresentem características diferentes quando comparadas com as empresas ocidentais em geral. De outro lado, devido justamente a essas diferenças que as empresas japonesas, como as multinacionais que têm atuação no Exterior, enfrentam problemas de adaptação e de acomodação; ou de como fazer valer esses princípios, que são muito acatados no Japão, dentro de um contexto social e econômico diferente, ou uma outra alternativa é readaptar esses princípios para que a sociedade acolhedora os aceite. De maneira que nessas últimas duas décadas, empresários japoneses estão passando por essa fase de aprendizado e de ensaio e tentativa em sua atuação no Exterior, principalmente nos países do sudeste da Ásia e, mais recentemente, nos países da América do Sul.

Da mesma maneira, os empresários japoneses no Brasil estão passando por essa fase de adaptação e de ensaios. Da presente fase, espera-se que surjam 
aigumas formas, alguns estilos de administração condizentes com o contextu social e econômico do Brasil e que essa experiência também seja positiva e constitua uma contribuição para o empresariado nacional brasileiro.

\section{Sisiema dual de comunicação}

As empresas multinacionais têm geralmente problema de comunicação, ou mais precisamente, do sistema dual de comunicação, dualidade essa tanto na comunicação como no processo decisório. No Brasil temos exemplos muito preciosos nessé sentido. Úm exemplo é da Cooperativa Agrícola de Cotia que foi fundada há mais de 50 anos por um grupo de oitenta e três familias japonesas. No início. a comunicação era feita só em japonès para defender interesses desses lavradores japoneses. Com o crescimento gradativo da Cooperativa, ela foi aceitando os associaldos brasileiros, isto é, de origem não japonesa e de outras nacionalidades, de maneira que a língua japonesa deixou de ser a língua principal de comunicação e naturalmente teve que recorrer ao português. $O$ japonês e o português jassaram a constituir um sistema de comunicação dual dentro da Cooperativa, seja no nivel dos cooperados, seja no nível de gerentes de depósitos regionais, ou ainda no nível de representantes de bairros e até no nivel da própria diretoria.

Uma organização gigantesca, como a de Cotia, funcionou e, ainda, funciona em certos aspectos sob o sistema dual de comunicação.

Nas situações bi-culturais ou interculturais, a tradução pode ajudar, mas não é suficiente para solucionar o problema, por que o principal não está na língua, mas está atrás da língua. A língua serve para comunicação verbal, porém atrás da língua está a própria cultura, o background cultural, que faz com que as pessoas se entendam. Nessas situaçōes bi-cuiturais, eu acredito que a compreensão das duas culturas em jogo, ou dois contextos culturais, se torna mais importante, tanto no sistema de decisão como no sistema de comunicação.

Un fator que pode pesar positivamente no desfecho desse processo de adaptação é a presença das gerações brasileiras de origem japonesa. Apreciáveis contingentes de ascendência japonesa estão atuando nas empresas japonesas aqui instaladas, ocupando, inclusive, postos de comando de nível médio.

Conhecedores, em maior ou menor grau, dos padrões japoneses de comportamento, esses brasileiros de origem japonesa representam, sem dúvida, canais importantes de comunicação, principalmente, quando se tratam dos casos de "joint-venture" 